\title{
Tuberculosis awareness in Gezira, Sudan: knowledge, attitude and practice case-control survey
}

\author{
M.M.A. Suleiman, ${ }^{7}$ N. Sahal, ${ }^{7}$ M. Sodemann, ${ }^{2}$ A. Elsony ${ }^{3}$ and A. R. Aro ${ }^{7}$
}

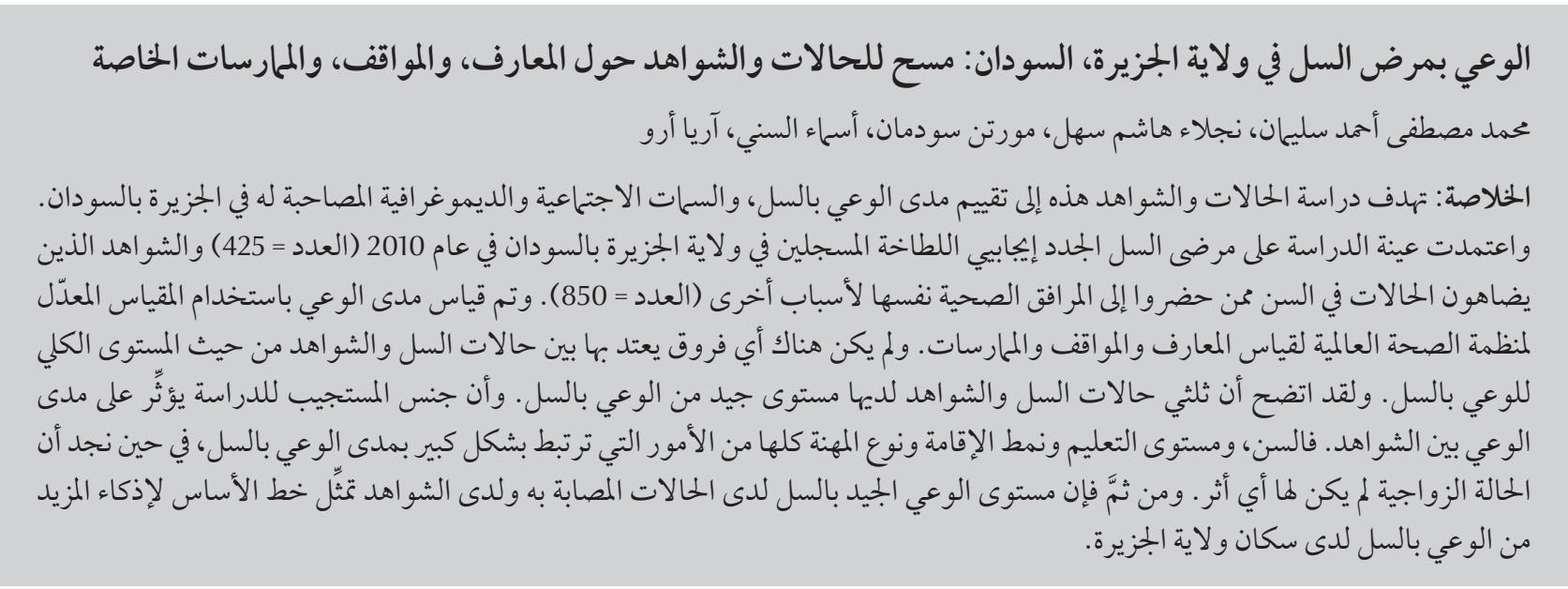

ABSTRACTThiscase-controlstudyaimed toassesstuberculosis(TB)awarenessanditsassociated sociodemographic characteristics in Gezira, Sudan. New smear-positive TB patients registered in Gezira in $2010(n=425)$ and agematched controls who attended the same health facilities for other reasons $(n=850)$ formed the study sample. Awareness was measured using a modified standard World Health Organization TB knowledge, attitude and practice instrument. There was no significant difference between TB cases and the controls in overall levels of TB awareness. About two-thirds of TB cases and controls had good TB awareness. Respondents' sex was associated with awareness among the controls. Age, level of education, type of residence and type of occupation were significantly associated with TB awareness, whereas marital status had no effect. The good level of TB awareness found among TB cases and controls is a baseline for further TB awareness-raising among the Gezira population.

Sensibilisation à la tuberculose dans l'état de Gézira (Soudan) : enquête cas-témoin sur les connaissances, les attitudes et les pratiques

RÉSUMÉ La présente étude cas-témoin visait à évaluer la sensibilisation à la tuberculose et les caractéristiques sociodémographiques associées dans l'état de Gézira (Soudan). L'échantillon de l'étude était composé de nouveaux patients à frottis positifs pour la tuberculose au Gézira en $2010(n=425)$ et de témoins appariés pour l'âge qui consultaient dans les mêmes établissements de santé pour d'autres motifs $(n=850)$. Le degré de sensibilisation à la maladie a été mesuré à l'aide de l'instrument standard modifié de l'Organisation mondiale de la Santé évaluant les connaissances, les attitudes et les pratiques en matière de tuberculose. Aucune différence significative n'a été observée entre les patients tuberculeux et les témoins dans les niveaux généraux de sensibilisation à la tuberculose. Environ deux tiers des patients tuberculeux et des témoins avaient un niveau de sensibilisation à la tuberculose satisfaisant. Dans le groupe des témoins, les hommes et les femmes n'avaient pas le même niveau de sensibilisation à la question. L'âge, le niveau d'études, le type de résidence et la profession étaient des facteurs nettement corrélés à la sensibilisation à la tuberculose, contrairement à la situation matrimoniale. Le niveau satisfaisant de sensibilisation à la tuberculose observé chez les patients atteints de tuberculose est un point de départ pour l'augmentation de la sensibilisation à cette maladie dans la population du Gézira.

'Unit for Health Promotion Research, University of Southern Denmark, Esbjerg, Denmark(Correspondence to M.M.A. Suleiman: msuleiman@ health.sdu.dk). ${ }^{2}$ Department of Infectious Diseases, Odense University Hospital, Odense, Denmark. ${ }^{3}$ Epidemiological Laboratory, Khartoum, Sudan. Received: 28/11/12; accepted: 07/05/13 


\section{Introduction}

Tuberculosis (TB) is among the top 10 causes of global mortality $[1,2]$, and in Africa the situation has worsened over the past 2 decades owing to the HIV/ AIDS epidemic $[3,4]$. In Sudan the incidence of TB is 180 cases per 100000 population at risk, which puts Sudan among the high-prevalence countries for TB in the Eastern Mediterranean Region [5]. Gezira State is one of the high TB burden states of Sudan, and further, there is high default rate from treatment (12.8\% in the year 2010). In 2007 Sudan overall was reported to have a TB case detection rate of $30 \%$ [6], far below the global target of $70 \%$, and the case detection rate in Gezira State in the same year was 39.7\% [7]. This low detection rate may in part be due to factors which hinder patients' access to care and increase default rates among those who start treatment.

The role of human behaviour in health and illness has been increasingly recognized [8-10]. Knowledge, attitude and practice surveys concerning TB can identify knowledge gaps, cultural beliefs or behavioural patterns that may facilitate understanding and action as well as pose problems or create barriers for TB control. The data collected enable programme managers to set $\mathrm{TB}$ programme priorities, to estimate the resources required for various activities, to select the most effective communication channels and messages, to establish baseline levels and to measure change that result from interventions [11]. Based on the literature we know that poorer socioeconomic conditions and lack of awareness of TB prevention and symptoms are risk factors for TB infection [12]. In addition, psychosocial issues such as lack of knowledge, low risk perception and illness perceptions such as social and cultural stigma as well as poor access to treatment facilities are associated with poorer TB-related behaviours and poorer adherence to $\mathrm{TB}$ treatment $[6,13]$.
The aims of the study were to assess $\mathrm{TB}$ awareness among $\mathrm{TB}$ cases and controls in Gezira, Sudan, and to determine the relationship between respondents' sociodemographic characteristics and their level of TB awareness. The goal was to contribute to knowledge about barriers to the success of the TB control programme, to inform programme managers and decision-makers and to provide a baseline for needed health promotion strategies and activities to reduce TB incidence among the Gezira population. The information gathered will facilitate the development of effective interventions that fit the socioeconomic, cultural and psychosocial characteristics of the local population and societal context.

\section{Methods}

\section{Study setting}

This study was carried out in Gezira State, which is one of the 17 states in Sudan. Gezira State lies between the Blue and the White Nile rivers in the east-central region of Sudan. It has an area of $27549 \mathrm{~km}^{2}$ and population of about 2796330 . The structure of the health-care system in Gezira State is based on primary health care and the health area concept, which is conceived as a decentralized health-care system able to integrate at district level.

\section{Sample}

A case-control study design was used. The cases were all new smear-positive TB cases diagnosed in the TB microscopy units in Gezira State in the period from January to June 2010, and for each case 2 controls were selected. The sample size was calculated for cases from the equation $n=z^{2} p q / d^{2}$, where $n=$ sample size, $z=$ level of confidence $=1.96, P=$ $0.5, q=1-p=0.5, d=$ desired margin of error $=0.05$. The required sample size was estimated as (1.96) (1.96) (0.5) $(0.5) /(0.05)^{2}=384$ patients; $10 \%$ of the calculated sample size was added to allow for non-response. Thus, the sample sizes were 425 patients and 850 controls. The sample size was divided between the health-care units according to the number of registered patients from January to December 2010. For each patient 2 age-matched controls were selected randomly from people attending the same heath facility for any other purpose. Other patients attending the health facility were used since there is no civil registry from which controls could be drawn. These control patients were selected randomly from the health facility clinic registry book during the same time period as the patients were selected.

\section{Data collection}

The sociodemographic characteristics (age, sex, residence, occupation, level of education, crowding, housing condition, etc.) and the level of TB awareness of participants were measured using a standard modified World Health Organization TB instrument for knowledge, attitude and practice surveys (28 more questions were added to the questionnaire and 5 of the existing questions were modified) [11]. The interview instrument was tested in a pilot study.

The fieldwork took place in Gezira State, Sudan, in the period from December 2010 to December 2011 by 14 health professionals who were trained in how to use the data gathering tools. A written consent was taken from the participants. The objectives, process and expected outcome of the research were explained to the participants and their right to withdraw from the study at any time without any consequences for their current care was explained. Absolute confidentiality of the information gathered was followed before, during and after finishing the study.

\section{Data analysis}

The assessment of the level of TB awareness among the TB cases and controls was based on the summation of the correct answers for the questions which 
measured 9 aspects of awareness about TB: having enough information about TB; types of TB; methods of transmission; TB symptoms and signs; methods of TB prevention; TB treatment; TB vaccination; people at risk for $\mathrm{TB}$; and cost of TB treatment and diagnosis. For analysis, awareness for all $\mathrm{TB}$ cases and controls was categorized into 4 levels based on the Likert-scale responses (9 points): very poor $(<2$ points), poor (2-4 points), good (5-7 points) and very good awareness ( $8-9$ points). Cronbach alpha was calculated for the TB awareness scale showing the reliability of 0.73 for the 20 items included in the scale.

The analysis of the quantitative data was done using SPSS, version 19.0. To calculate the frequency values descriptive statistics was used, and percentages were used to express the values for qualitative variables. The chi-squared test was used to compare between groups for the qualitative data. $P$-values $<0.05$ were considered statistically significant. Logistic regression was conducted to predict multivariate relation of sociodemographic characteristics and $\mathrm{TB}$ awareness.

\section{Results}

\section{Sociodemographic characteristics of TB cases and controls}

The proportion of men was slightly higher among the $\mathrm{TB}$ cases than among the controls. Marital status distribution was similar as half of the cases and half of the controls were married and one-third of them were single. There was a statistically significant difference in the level of education between the groups (Table 1); 35\% of the cases had no school education and $21 \%$ had high education level whereas the respective percentages among the controls were $18 \%$ and $54 \%$. Significantly more cases lived in the rural area than did the controls. Furthermore, significantly fewer cases were employees than the controls; somewhat less than half of both groups were without work.

Both the cases and controls primarily sought health care in government health facilities. Very few of either TB cases or controls sought health care either from traditional healers or in the private sector. The TB cases had significantly more often attended health-care facilities in the past year than the controls $(P<$ 0.05 ) (Table 1 ), although only $18 \%$ of them attended health facilities due to their TB disease (data not shown). A quarter of the TB cases and 13\% of controls had a family member who had TB, less than $20 \%$ of both TB cases and controls had neighbour who had TB and about $10 \%$ of both TB cases and controls had a friend who had TB.

\section{TB awareness}

Almost everyone (98\%) (both TB cases and the controls) had heard about TB. On the other hand, the groups differed significantly in the source of their TB knowledge; $54 \%$ of the controls mentioned the media more often and $33 \%$ of the cases mentioned the family slightly more often. As regards source of information, $34 \%$ of both the cases and controls knew about TB from healthcare workers.

Only about $30 \%$ of both the cases and controls stated that they had enough information about TB (Table 2). The cases and controls were similar in the extent to which they understood the TB information that they had received. TB was viewed as a common disease in $\mathrm{Su}$ dan by almost half of the TB cases and the controls. TB was agreed to be very serious by around one-third of both the $\mathrm{TB}$ cases and controls. The cases more often than controls answered that they did not know how common TB was or how serious it was. Most of the TB cases and the controls knew some of TB symptoms while one-third of both cases and controls knew all TB symptoms.

Around $70 \%$ of both TB cases and the controls knew the methods of TB transmission (Table 2). The methods of TB prevention were known by about two-thirds of both TB cases and controls. Around $80 \%$ of both TB cases and controls mentioned that anyone can get $\mathrm{TB}$ while $10 \%$ of both thought that TB was a disease only of poor people.

Nearly $90 \%$ of both TB cases and controls considered TB as a treatable disease and most knew that TB was treated by specific drugs given by government health facilities (Table 2). TB treatment and diagnosis was known to be free of charge by about $90 \%$ of TB cases and $80 \%$ of controls; a quarter of both TB cases and the controls stated that $\mathrm{TB}$ treatment was for 6 months while the others gave answers ranging from 1 month to lifelong. Some of the TB cases and the controls considered the duration of TB treatment as long or short without knowing exactly the period. Regarding TB vaccination, only one-third of TB cases and half of controls knew about the availability of vaccination against TB. More than two-thirds of those who knew about TB vaccination thought that the vaccine would prevent TB occurring.

Two-thirds of both TB cases and the controls had good awareness of $\mathrm{TB}$, while around 21.9 of $\mathrm{TB}$ cases and $16.7 \%$ of controls had very good awareness while around $1 \%$ of both groups had very poor awareness (Table 3). There was no significant difference between TB cases and controls in their overall level of their awareness about $\mathrm{TB}$.

\section{Univariate and multivariate analyses}

In the univariate analysis of the relationship of sociodemographic characteristics to TB awareness separately among cases and controls it was found that a respondent's sex was a factor among the controls but not among the TB cases, with men having better awareness than women (Table 4). Younger age, higher 


\begin{tabular}{|c|c|c|c|c|c|}
\hline \multirow[t]{2}{*}{ Variable } & \multicolumn{2}{|c|}{ TB cases } & \multicolumn{2}{|c|}{ Controls } & \multirow[t]{2}{*}{$P$-value } \\
\hline & No. & $\%$ & No. & $\%$ & \\
\hline \multicolumn{6}{|l|}{ Age group (years) } \\
\hline$<30$ & 158 & 37.2 & 329 & 38.7 & \multirow{3}{*}{0.69} \\
\hline $31-50$ & 194 & 45.6 & 390 & 45.9 & \\
\hline$>50$ & 73 & 17.2 & 131 & 15.4 & \\
\hline \multicolumn{6}{|l|}{ Sex } \\
\hline Male & 262 & 61.6 & 480 & 58.2 & \multirow{2}{*}{0.04} \\
\hline Female & 163 & 38.4 & 370 & 41.8 & \\
\hline \multicolumn{6}{|l|}{ Marital status } \\
\hline Married & 235 & 55.3 & 442 & 53.1 & \multirow{3}{*}{0.15} \\
\hline Single & 148 & 34.8 & 292 & 34.5 & \\
\hline Divorced or widowed & 42 & 9.9 & 116 & 12.4 & \\
\hline \multicolumn{6}{|l|}{ Education level } \\
\hline No school & 148 & 34.8 & 152 & 17.9 & \multirow{3}{*}{$<0.001$} \\
\hline Middle level of education & 155 & 36.5 & 242 & 28.5 & \\
\hline High level of education & 122 & 21.1 & 455 & 53.6 & \\
\hline \multicolumn{6}{|l|}{ Type of residency } \\
\hline Town & 151 & 35.5 & 392 & 46.1 & \multirow{3}{*}{$<0.001$} \\
\hline Village & 242 & 56.9 & 429 & 50.5 & \\
\hline Other & 32 & 7.5 & 29 & 3.4 & \\
\hline \multicolumn{6}{|l|}{ Occupation } \\
\hline Non-worker & 199 & 46.8 & 364 & 42.8 & \multirow{5}{*}{$<0.001$} \\
\hline Employee & 21 & 4.9 & 143 & 16.8 & \\
\hline Labourer & 98 & 23.1 & 157 & 18.5 & \\
\hline Self-employed & 91 & 21.4 & 162 & 19.1 & \\
\hline Other & 16 & 3.8 & 24 & 2.8 & \\
\hline \multicolumn{6}{|l|}{ Distance from nearest health facility $(\mathrm{km})$} \\
\hline$<5$ & 244 & 57.4 & 547 & 62.0 & \multirow{4}{*}{0.032} \\
\hline $5-10$ & 79 & 18.6 & 149 & 17.9 & \\
\hline$>10$ & 31 & 7.3 & 58 & 6.8 & \\
\hline Not near facility & 71 & 16.7 & 96 & 11.3 & \\
\hline \multicolumn{6}{|l|}{ No. of times seeking health care last year } \\
\hline 0 & 79 & 18.8 & 381 & 44.8 & \multirow{4}{*}{$<0.001$} \\
\hline $1-3$ & 258 & 61.3 & 430 & 50.6 & \\
\hline $4-7$ & 83 & 19.7 & 37 & 4.4 & \\
\hline$>7$ & 6 & 0.2 & 2 & 0.2 & \\
\hline $\begin{array}{l}\text { Type of health facilities for seeking health } \\
\text { care }\end{array}$ & \multicolumn{2}{|c|}{$(n=346)$} & \multicolumn{2}{|c|}{$(n=470)$} & \multirow{4}{*}{$<0.001$} \\
\hline Government & 327 & 94.5 & 449 & 95.5 & \\
\hline Non-government & 12 & 3.5 & 15 & 3.2 & \\
\hline Other & 7 & 2.0 & 6 & 1.3 & \\
\hline
\end{tabular}

level of education, living in town settings and being an employer or employee were significantly associated with higher level of TB awareness among both the TB cases and controls, while marital status had no effect on the level of TB awareness among $\mathrm{TB}$ cases or controls (Table 4).

In the multinomial logistic regression analysis, to avoid unexpected singularity, the very poor and poor categories of awareness were merged (only 13 participants had very poor TB awareness). The crude odds ratios for the sociodemographic characteristics 


\begin{tabular}{|c|c|c|c|c|c|}
\hline \multirow[t]{2}{*}{ Item } & \multicolumn{2}{|c|}{ TB cases } & \multicolumn{2}{|c|}{ Controls } & \multirow[t]{2}{*}{$P$-value } \\
\hline & No. & $\%$ & No. & $\%$ & \\
\hline \multicolumn{6}{|l|}{ Know TB a common disease in Sudan } \\
\hline Yes & 201 & 47.3 & 406 & 47.8 & \multirow{3}{*}{0.47} \\
\hline No & 120 & 28.2 & 308 & 36.2 & \\
\hline Don't know & 104 & 24.5 & 136 & 16.0 & \\
\hline \multicolumn{6}{|l|}{ How serious a disease is $T B$} \\
\hline Very serious & 134 & 31.5 & 251 & 29.5 & \multirow{4}{*}{$<0.001$} \\
\hline Somewhat serious & 170 & 40.0 & 351 & 41.3 & \\
\hline Not very serious & 50 & 11.8 & 167 & 19.6 & \\
\hline Don't know & 71 & 16.7 & 81 & 9.5 & \\
\hline \multicolumn{6}{|l|}{ How serious is the problem of TB in Sudan } \\
\hline Very serious & 128 & 30.1 & 220 & 25.9 & \multirow{4}{*}{$<0.001$} \\
\hline Somewhat serious & 147 & 34.6 & 303 & 35.6 & \\
\hline Not very serious & 59 & 13.9 & 178 & 20.9 & \\
\hline Don't know & 91 & 21.4 & 149 & 17.6 & \\
\hline \multicolumn{6}{|l|}{ Know types of TB } \\
\hline Yes & 15 & 3.5 & 32 & 3.8 & \multirow{2}{*}{0.43} \\
\hline No & 410 & 96.5 & 818 & 96.2 & \\
\hline \multicolumn{6}{|l|}{ Know signs and symptoms of TB } \\
\hline All & 119 & 29.5 & 284 & 33.4 & \multirow{3}{*}{0.50} \\
\hline Some & 279 & 65.5 & 500 & 58.8 & \\
\hline None & 27 & 5.0 & 66 & 8.6 & \\
\hline \multicolumn{6}{|l|}{ Have enough information about TB } \\
\hline Yes & 124 & 29.2 & 251 & 29.2 & \multirow{3}{*}{0.55} \\
\hline No & 193 & 45.4 & 431 & 50.7 & \\
\hline Don't know & 108 & 25.4 & 168 & 19.8 & \\
\hline \multicolumn{6}{|l|}{ Information about TB was understandable } \\
\hline Yes, fully & 85 & 20.0 & 144 & 18.0 & \multirow{3}{*}{$<0.001$} \\
\hline Yes, partially & 84 & 19.8 & 322 & 37.9 & \\
\hline No & 266 & 41.1 & 384 & 45.2 & \\
\hline Reasons for not understanding TB information & \multicolumn{2}{|c|}{$(n=266)$} & \multicolumn{2}{|c|}{$(n=730)$} & \multirow{5}{*}{0.04} \\
\hline Difficult & 46 & 17.3 & 70 & 18.2 & \\
\hline Too much & 38 & 14.3 & 100 & 26.0 & \\
\hline Incomplete & 63 & 23.7 & 189 & 49.2 & \\
\hline Other & 119 & 44.7 & 25 & 0.6 & \\
\hline \multicolumn{6}{|l|}{ Know methods of TB transmission } \\
\hline All & 301 & 70.8 & 609 & 71.5 & \\
\hline Some & 100 & 23.5 & 201 & 23.6 & 0.75 \\
\hline None & 24 & 5.7 & 40 & 4.9 & \\
\hline Know methods of TB prevention & & & & & \\
\hline All & 285 & 67.1 & 576 & 67.8 & \\
\hline Some & 129 & 30.4 & 264 & 31.1 & 0.36 \\
\hline None & 6 & 2.5 & 10 & 1.1 & \\
\hline Know people at risk & & & & & \\
\hline All & 331 & 77.9 & & 74.0 & \\
\hline Some & 39 & 9.2 & 105 & 12.4 & 0.02 \\
\hline None & 55 & 13.9 & 116 & 13.6 & \\
\hline
\end{tabular}




\begin{tabular}{|c|c|c|c|c|c|}
\hline \multirow[t]{2}{*}{ Item } & \multicolumn{2}{|c|}{ TB cases } & \multicolumn{2}{|c|}{ Controls } & \multirow[t]{2}{*}{$P$-value } \\
\hline & No. & $\%$ & No. & $\%$ & \\
\hline \multicolumn{6}{|c|}{ Know TB curable } \\
\hline Yes & 372 & 87.5 & 719 & 84.6 & \multirow{3}{*}{0.37} \\
\hline No & 13 & 3.1 & 32 & 3.8 & \\
\hline Don't know & 40 & 9.4 & 99 & 11.6 & \\
\hline \multicolumn{6}{|c|}{ Know methods of TB treatment } \\
\hline Yes & 352 & 82.8 & 703 & 82.7 & \multirow{2}{*}{0.63} \\
\hline No & 73 & 17.1 & 147 & 17.3 & \\
\hline \multicolumn{6}{|c|}{ Know places where to find TB treatment } \\
\hline Yes & 389 & 91.5 & 774 & 91.1 & \multirow{2}{*}{0.49} \\
\hline No & 36 & 8.5 & 76 & 8.9 & \\
\hline \multicolumn{6}{|c|}{ Know vaccination against TB available } \\
\hline Yes & 135 & 31.8 & 408 & 48.0 & \multirow{3}{*}{$<0.001$} \\
\hline No & 49 & 11.5 & 66 & 7.8 & \\
\hline Don't know & 241 & 56.7 & 376 & 44.2 & \\
\hline \multicolumn{6}{|c|}{ Know TB vaccination protective } \\
\hline Yes & 110 & 81.5 & 360 & 88.2 & \multirow{3}{*}{$<0.001$} \\
\hline No & 25 & 18.5 & 34 & 8.3 & \\
\hline Don't know & 0 & 0.0 & 10 & 3.5 & \\
\hline \multicolumn{6}{|c|}{ Know cost of TB diagnosis in Sudan } \\
\hline Yes & 373 & 87.6 & 612 & 72.0 & \multirow{2}{*}{$<0.001$} \\
\hline No & 52 & 12.4 & 238 & 28.0 & \\
\hline \multicolumn{6}{|c|}{ Know cost of TB treatment in Sudan } \\
\hline Yes & 367 & 86.4 & 616 & 72.5 & \multirow{2}{*}{$<0.001$} \\
\hline No & 58 & 13.6 & 234 & 27.5 & \\
\hline
\end{tabular}

associated with $\mathrm{TB}$ awareness showed that high education level and being married were associated with very good awareness among the TB cases. Younger age, living in town settings, high education level and being an employer were associated with very good awareness among the controls (Table 5). High education level, being married and being an employer were associated with good awareness among the TB cases, while among controls high education was associated with good awareness. Respondents' sex had no effect on the level of awareness among either the TB cases or controls. Marital status had no effect on the awareness among the controls.

\begin{tabular}{|c|c|c|c|c|c|}
\hline \multicolumn{6}{|c|}{$\begin{array}{l}\text { Table } 3 \text { Level of tuberculosis (TB) awareness among TB patients }(n=425) \text { and } \\
\text { controls }(n=850)\end{array}$} \\
\hline \multirow[t]{2}{*}{ Level of TB awareness } & \multicolumn{2}{|c|}{ TB cases } & \multicolumn{2}{|c|}{ Controls } & \multirow[t]{2}{*}{$P$-value } \\
\hline & No. & $\%$ & No. & $\%$ & \\
\hline Very poor & 5 & 1.2 & 8 & 0.9 & \multirow{5}{*}{0.81} \\
\hline Poor & 48 & 11.3 & 124 & 14.6 & \\
\hline Good & 279 & 65.6 & 576 & 67.8 & \\
\hline Very good & 93 & 21.9 & 142 & 16.7 & \\
\hline Total & 425 & 100.0 & 850 & 100.0 & \\
\hline
\end{tabular}

\section{Discussion}

Awareness is a very important parameter to be assessed in order to provide baseline data to assist decision-makers to plan and deliver of an effective TB control programme. The present study revealed some important aspects of TB awareness among the Sudanese population.

In this study in Gezira State there was no significant difference between TB cases and controls in their overall levels of TB awareness. About twothirds of TB cases and controls had good TB awareness. Sex had an effect on awareness among the controls but not among the TB cases. Age, level of education, type of residence and type of occupation were significantly associated with the level of TB awareness, 


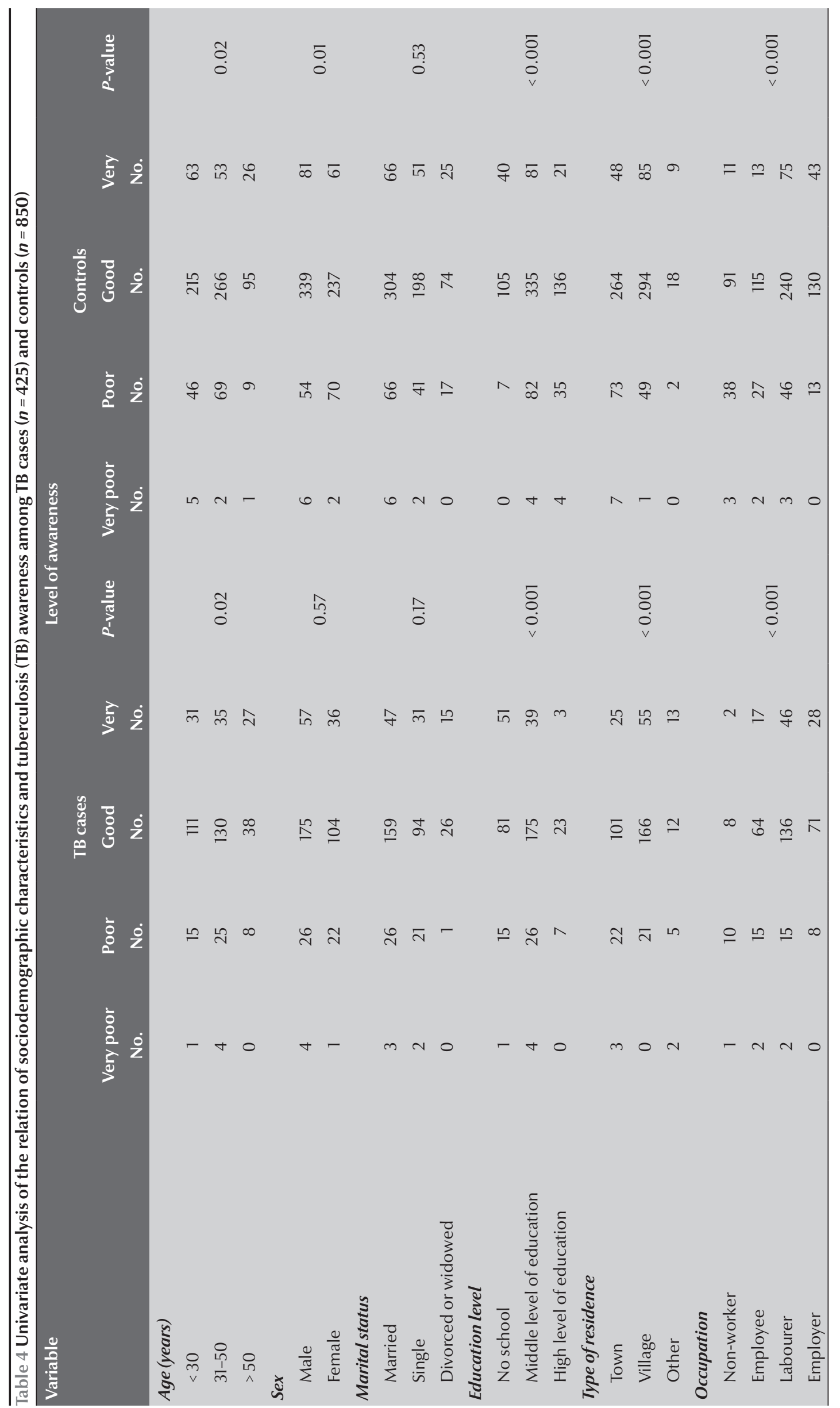




\begin{tabular}{|c|c|c|c|c|c|c|}
\hline \multirow{2}{*}{$\begin{array}{l}\text { Level of TB awareness/ } \\
\text { variable }\end{array}$} & \multicolumn{3}{|c|}{ TB cases } & \multicolumn{3}{|c|}{ Controls } \\
\hline & OR & $95 \% \mathrm{Cl}$ & $P$-value & OR & $95 \% \mathrm{Cl}$ & $P$-value \\
\hline \multicolumn{7}{|l|}{ Poor awareness ${ }^{\mathrm{a}}$} \\
\hline \multicolumn{7}{|l|}{ Age (years) } \\
\hline$<30$ & 0.17 & 0.03-1.08 & 0.06 & 2.76 & $1.02-7.45$ & 0.05 \\
\hline $31-50$ & 0.81 & $0.27-2.34$ & 0.70 & 1.47 & $0.60-3.57$ & 0.40 \\
\hline \multicolumn{7}{|l|}{ Sex } \\
\hline Male & 0.88 & $0.31-2.68$ & 0.81 & 1.46 & $0.79-2.73$ & 0.23 \\
\hline \multicolumn{7}{|l|}{ Marital status } \\
\hline Married & 0.21 & $0.05-0.82$ & 0.03 & 0.62 & $0.29-1.34$ & 0.22 \\
\hline Single & 0.30 & $0.06-1.64$ & 0.17 & 0.75 & $0.31-1.79$ & 0.51 \\
\hline \multicolumn{7}{|l|}{ Education level } \\
\hline No school & 6.16 & $1.43-25.8$ & 0.02 & 3.63 & $1.53-8.64$ & 0.00 \\
\hline Middle & 2.89 & $0.60-14.0$ & 0.19 & 2.12 & $1.02-4.41$ & 0.04 \\
\hline \multicolumn{7}{|l|}{ Residence } \\
\hline Town & 0.82 & $0.22-3.18$ & 0.77 & 0.21 & $0.06-0.72$ & 0.01 \\
\hline Village & 0.27 & $0.07-0.99$ & 0.05 & 0.43 & $0.13-1.47$ & 0.18 \\
\hline \multicolumn{7}{|l|}{ Occupation } \\
\hline Non-worker & 0.38 & $0.04-5.08$ & 0.43 & 0.42 & $0.14-1.28$ & 0.13 \\
\hline Employee & 0.17 & $0.03-0.74$ & 0.06 & 0.35 & $0.14-0.88$ & 0.03 \\
\hline Labourer & 0.81 & $0.27-1.70$ & 0.70 & 1.01 & $0.45-2.24$ & 0.98 \\
\hline \multicolumn{7}{|l|}{ Good awareness $^{\mathrm{a}}$} \\
\hline \multicolumn{7}{|l|}{ Age (years) } \\
\hline$<30$ & 1.47 & $0.62-3.47$ & 0.38 & 1.13 & $0.61-2.09$ & 0.71 \\
\hline $31-50$ & 1.00 & $0.47-2.10$ & 1.00 & 0.97 & $0.56-1.69$ & 0.93 \\
\hline \multicolumn{7}{|l|}{ Sex } \\
\hline Male & 1.09 & $0.62-1.93$ & 0.77 & 1.38 & 0.96-1.99 & 0.08 \\
\hline \multicolumn{7}{|l|}{ Marital status } \\
\hline Married & 0.33 & $0.11-1.03$ & 0.06 & 1.42 & $0.85-2.37$ & 0.18 \\
\hline Single & 0.25 & $0.07-0.86$ & 0.03 & 1.38 & $0.77-2.47$ & 0.28 \\
\hline \multicolumn{7}{|l|}{ Education level } \\
\hline No school & 1.10 & $0.56-2.15$ & 0.78 & 1.14 & $0.64-2.03$ & 0.65 \\
\hline Middle & 2.09 & $1.10-3.99$ & 0.03 & 1.63 & $1.05-2.51$ & 0.03 \\
\hline \multicolumn{7}{|l|}{ Residence } \\
\hline Town & 2.35 & $0.90-6.09$ & 0.08 & 0.66 & $0.22-1.92$ & 0.44 \\
\hline Village & 2.05 & $0.82-5.11$ & 0.12 & 1.39 & $0.47-4.10$ & 0.55 \\
\hline \multicolumn{7}{|l|}{ Occupation } \\
\hline Non-worker & 0.33 & $0.11-0.98$ & 0.05 & 0.57 & $0.32-1.01$ & 0.05 \\
\hline Employee & 0.66 & $0.33-1.32$ & 0.24 & 0.60 & $0.35-1.03$ & 0.07 \\
\hline Labourer & 0.93 & $0.45-1.89$ & 0.83 & 0.86 & $0.51-1.45$ & 0.58 \\
\hline
\end{tabular}

${ }^{a}$ Reference category = very good awareness.

Reference categories: age => 50 years; sex =female; marital status = divorced/widowed; educational level = high school; residence =camp; occupation = employer $O R=$ odds ratio; $C I=$ confidence interval. 
while marital status had no effect. Males, highly educated persons, those being either employers or employees had very good awareness and so did those living in towns.

On assessing the degree of TB awareness, the majority of both $\mathrm{TB}$ cases and controls had good awareness. This was similar to the situation in Khartoum State [Osman A, unpublished report to Ministry of Health Khartoum, 2006]. The general good level of awareness among respondents can probably be explained by the high prevalence of TB in Sudan, which means that people have more experience of the disease or may seek out knowledge about the different aspects of the disease in order to avoid it. Another explanation might be an active TB control programme in Sudan, which uses the effective directly observed treatment, shortcourse (DOTS) for TB treatment. This might improve TB patients' and their relatives' knowledge about the disease through the regular educational and/or counselling sessions. Other methods might have a similar effect such as the World TB Day celebrations in Sudan and public education/health promotion messages. A diagnosis of TB may motivate cases to search for more information. Despite the good level of awareness, only one-third of both cases and controls reported having enough information about TB, indicating that there is a perceived need for more information.

In this study respondents' sex had a significant role in TB-related awareness among the controls but not among the TB cases. This could be because male and female TB cases had a similar level of education, as was found in Khartoum State [Osman A, unpublished report to Ministry of Health Khartoum, 2006]. This finding is similar to the findings reported in the literature, e.g. from China, where women were less likely than men to get information about TB and share it with others on their own initiative [14].
Educational level affected the level of TB awareness among $\mathrm{TB}$ cases and the controls; the level of TB awareness increased when the educational level increased. Persons who had high secondary school or higher educational level were more likely to have very good awareness among both TB cases and controls. This was similar to what was found in Khartoum State [15] and in Libya, where the TB knowledge scores were directly proportional to level of education [16]. The controls in our study were more highly educated than TB cases and the media was their main source of their TB information whereas TB cases more often had their information from health-care workers, i.e. TB patients' awareness came as a result of having the disease.

We found that people who lived in towns among controls were more likely to have very good TB awareness than people who lived in rural areas. This can be explained by better accessibility to different sources of TB information, such the media, in town settings than in the rural areas. However, among the $\mathrm{TB}$ cases the area of residence did not have an effect on their TB awareness. These findings are similar to what was found in Pakistan, where healthseeking behaviour was better in the urban areas [17], and also to what was found in Ethiopia, where lack of TB knowledge was more evident among the rural population [18].

In this study, among the controls, being an employer or employee was related to very good awareness about TB compared with non-workers; however, among the cases occupational status did not make a difference in TB awareness. This result is in line with what was found in Khartoum State [Osman A, unpublished report to Ministry of Health Khartoum, 2006] as well as in West Africa [6].

The population's level of the TB awareness is known to have a positive impact on prevention of TB [6]. Having more knowledge about methods of TB transmission and about ways of preventing the disease helps in decreasing the TB risk [19]. However, this study found no significant difference in TB awareness among $\mathrm{TB}$ cases and controls in Gezira State. This similarity in the TB awareness can be justified by the fact that the TB cases probably acquired this knowledge after they were diagnosed with $\mathrm{TB}$ and received health education and/or counselling as a part of TB management using DOTS. The role of health education in raising knowledge about TB is highly appreciated in initiatives to fight TB [20]. This overall good level of TB awareness found among TB cases and the controls can function as a baseline for further $\mathrm{TB}$ awareness-raising among the Gezira population. Nevertheless there were important areas of knowledge missing, such as mode of TB transmission, especially among TB cases, TB prevention methods and types of TB, all of which are vital issues in TB knowledge. Health education and health promotion as continuous processes can maintain and further elevate the level of awareness [7] and thus also motivate patients both to seek treatment and to adhere to it.

The strengths of the study were that it addressed patient-related factors influencing TB prevention and control strategies. It included a large proportion of participants (425 TB cases and 850 controls) and the data were collected by trained health-care workers. On the other hand, the study limitations were potential social desirability bias in answering the interview questions, and a possible bias by the health professionals collecting the data, who might have helped interviewees to answer the questionnaire. The study did not address health-care workers' knowledge, attitudes and practices regarding TB and its treatment. Furthermore, the study was conducted only in Gezira State and the findings therefore may not be generalizeable to other Sudanese States. 


\section{Conclusion}

This study showed that $\mathrm{TB}$ cases and the controls in Gezira State, Sudan, had a good level of awareness about the disease. Male sex was associated with better awareness among the controls but not among the TB cases. Younger age, higher level of education, living in town settings and being an employee or employer were significantly associated with better a level of $\mathrm{TB}$ awareness among both TB cases and controls, while marital status had no effect. This awareness needs to be maintained to facilitate future prevention and control of the disease. Media and health-care workers were the most important sources of TB information; their health education resources and role need to be strengthened. There is a need to increase awareness among those with lower educational level and socioeconomic status and those living in rural areas.

\section{References}

1. The world health report 200. Health systems: improving performance. Geneva, World Health Organization, 2000.

2. Murray CJ, Lopez AD. Mortality by cause for eight regions of the world: Global Burden of Disease Study. Lancet, 1997, 349:1269-1276.

3. Global tuberculosis control. WHO Report 2001. Geneva, World Health Organization, 2001 (WHO/CDS/TB/2001.287).

4. De Cock KM et al. Tuberculosis and HIV infection in subSaharan Africa. Journal of the American Medical Association, 1992, 268:1581-1587.

5. Crofton J. Reforms to the health sector must retain vertical programmes like those for tuberculosis. British Medical Journal, 2000, 320:1726.

6. Adherence to long-term therapies: evidence for action. Geneva, World Health Organization, 2003.

7. Tuberculosis control programme. Annual report 2007. Khartoum, Sudan, State Ministry of Health Preventive Medicine Directorate, 2007.

8. Quilala D. Knowledge, attitudes and practices (KAP) of public school teachers in llocos Sur regarding tuberculosis. Philippine Journal of Internal Medicine, 2005, 43:159-167.

9. Petrie KJ, Weinman JA. Perceptions of health and illness. Amsterdam, Harwoord Academic Publishers, 1998.

10. Bennet P, Murphy S. Psychology and health promotion. Buckingham, United Kingdom, Open University Press, 1997.

11. Advocacy, communication and social mobilization for TB control. A guide to developing knowledge, attitude and practice surveys. Geneva, World Health Organization, 2008 (WHO/HTM/ STB/2008.46).
12. Woith WM, Larson JL. Delay in seeking treatment and adherence to tuberculosis medications in Russia: a survey of patients from two clinics. International Journal of Nursing Studies, 2008, 45(8):1163-1174.

13. Suleiman MMA, Sahal N, Sodemann M, Aro AR. Tuberculosis stigma in Gezira State, Sudan: a case-control study. International Journal of Tuberculosis and Lung Disease, 2013, 17(3):388-393.

14. Wang J et al. Gender difference in knowledge of tuberculosis and associated health-care seeking behaviors: a cross-sectional study in a rural area of China. BMC Public Health, 2008, 8:354. doi: 10.1186/1471-2458-8-354.

15. Mohamed Al et al. Knowledge of tuberculosis: a survey among tuberculosis patients in Omdurman, Sudan. Sudanese Journal of Public Health, 2007, 2:21-28.

16. Solliman A et al. Assessment of knowledge towards tuberculosis among general population in North East Libya. Journal of Applied Pharmaceutical Science, 2012, 2:24-30.

17. Mushtaq MU et al. Urban-rural inequities in knowledge, attitudes and practices regarding tuberculosis in two districts of Pakistan's Punjab province. International Journal for Equity in Health, 2011, 10:8.

18. Mesfin $\mathrm{M}$ et al. Community knowledge, attitudes and practices on pulmonary tuberculosis and their choice of treatment supervisor in Tigray, Northern Ethiopia. Ethiopian Journal of Health Development, 2005, 19:21-27.

19. Global tuberculosis control: surveillance, planning, financing. WHO report 2008. Geneva, World Health Organization, 2008.

20. An expanded DOTS framework for effective tuberculosis control. Geneva, World Health Organization, 2000. 